\title{
Erratum: Unprotected Anal Intercourse in HIV-Positive and HIV-Negative Gay Men: The Relevance of Sexual Arousability, Mood, Sensation Seeking, and Erectile Problems
}

In the article, "Unprotected Anal Intercourse in HIVPositive and HIV-Negative Gay Men: The Relevance of Sexual Arousability, Mood, Sensation Seeking, and Erectile Problems" by John Bancroft, M.D., Lori Carnes, M.A., and Erick Janssen, Ph.D., published in Archives of Sexual Behavior, Volume 34, Number 3 (June 2005), pp. 299-305, half of page 304 is missing. The complete page 304 appears on the next page.

The publisher and printer regret this error, which the printer assures us will not recur. 
the previous few months. They commented that "although little concern was voiced about penis size, there was frequent mention of problems with erection, especially in association with condom use... the inability to gain or maintain an erection while using a condom clearly led to occasional failure to use condoms and for some men, abandoning any attempt to use them at all" (p. 44). It was not clear, however, whether such problems were postseroconversion, but there were no indications that they were of recent onset. Both of these explanatory mechanisms are of sufficient potential relevance to HIV (and other STD) transmission, that they deserve more direct scrutiny in future research.

With the exception of erectile problems, and the associated trait measure, SIS1, none of our predictors of UAI risk distinguished HIV+ from HIV - gay men. Obviously, other personality-related factors may distinguish these groups, although so far the limited literature on this topic has failed to find such discriminators.

\section{APPENDIX: QUESTIONS AND METHODS USED TO DERIVE UAI SCORES}

\section{Part I: Frequency/HIV Status/Condom Use}

1. How often have you had anal intercourse in the past 6 months?

- Six choices: Not at all (0) to at least once a day (5).

2. When you have anal intercourse, how often are you the insertee ("bottom")?

- Five choices: "I don't have anal intercourse" (0); "never" (0.5); "sometimes" (1); "most of the time" (1.5); "every time" (2).

3. In the past 6 months, have you had anal intercourse with a man without knowing whether he was HIV positive or negative?

- Used for consistency purposes for 4 and 5.

4. If yes (had AI without knowing HIV status), how often would this have happened?

- Four choices ranging from "Once or twice" (1) to "More than 11 occasions" (2). Received a 0.5 if "No" to 3 .

5. If yes (i.e., had AI without knowing HIV status), how often would this have happened without wearing a condom?

- Five choices ranging from "Not at all" (.5) to "More than 10 occasions" (2). Received a 1 if "No" to 3. $(0-40)$.

Multiply 1, 2, 4, and 5 to get Part I sub-score

\section{Part II: Number of UAI Partners}

With how many men referred to in previous questions (casual partners or those having sex with others) did you have anal intercourse without using a condom?

- Score ranged from 0 to 40 . (Those with a count greater than 40 were recoded to 40 )

Sum Part I and Part II scores for the Anal Intercourse score $(0-80)$.

\section{ACKNOWLEDGMENT}

This study was made possible by NIMH Grant R01MH60519-02.

\section{REFERENCES}

Bancroft, J., Carnes, L., Janssen, E. J., Goodrich, D., \& Long, J. S. (2005). Erectile and ejaculatory problems in gay and heterosexual men. Archives of Sexual Behavior, 34, 285-297.

Bancroft, J., \& Janssen, E. (2000). The dual control model of male sexual response: A theoretical approach to centrally mediated erectile dysfunction. Neuroscience and Biobehavioral Reviews, 24, 571579.

Bancroft, J., Janssen, E., Strong, D., Carnes, L. C., Vukadinovic, Z., \& Long, J. S. (2003a). The relationship between mood and sexuality in heterosexual men. Archives of Sexual Behavior, 32, 217-230.

Bancroft, J., Janssen, E., Strong, D., Carnes, L., Vukadinovic, Z., \& Long, J. S. (2003b). Sexual risk taking in gay men: The relevance of sexual arousability, mood and sensation seeking. Archives of Sexual Behavior, 32, 555-572.

Bancroft, J., Janssen, E., Strong, D., \& Vukadinovic, Z. (2003). The relationship between mood and sexuality in gay men. Archives of Sexual Behavior, 32, 231-242.

Catalan, J., \& Meadows, J. (2000). Sexual dysfunction in gay and bisexual men with HIV infection: Evaluation, treatment and implications. AIDS Care, 12, 279-286.

Clement, U. (1992). Psychological correlates of unprotected intercourse among HIV-positive gay men. Journal of Psychology and Human Sexuality, 5, 133-155.

Crosby, R. A., Sanders, S. A., Yarber, W. L., Graham, C. A., \& Dodge, B. (2002). Condom use errors and problems among college men. Sexually Transmitted Diseases, 29, 552-557.

Darrow, W. W., Webster, R. D., Kurtz, S. P., Buckley, A. K., Patel, K. I., \& Stempel, R. R. (1998). Impact of HIV counseling and testing on HIV-infected men who have sex with men: The South Beach health survey. AIDS and Behavior, 2, 115-126.

Des Jarlais, D. C., \& Semaan, S. (2002). HIV prevention research: Cumulative knowledge or accumulating studies? Journal of Acquired Immune Deficiency Syndromes, 30, S1-S7.

Dupras, A., \& Morisset, R. (1993). Sexual dysfunction among HIVpositive gay males. Sexual and Marital Therapy, 8, 37-46.

Elford, J., Bolding, G., Maguire, M., \& Sherr, L. (2001). HIV positive and negative homosexual men have adopted different strategies for reducing the risk of HIV transmission. Sexually Transmitted Infections, 77, 224-225. 